\title{
Evidence of Anti-hyperglycemic and Anti-oxidant Effect of Passiflora edulis flavicarpa (Sims.) in Streptozotocin Induced Diabetic Rats
}

\author{
Subash PANCHANATHAN*, Jayanthi RAJENDRAN \\ Kerala University of Health Science, KMCT Medical College, Department of Biochemistry, Manassery, Calicut-673 602, Kerala, \\ India;subash15p@gmail.com (*orrespondingauthor)
}

\begin{abstract}
Diabetes mellitus is a worldwide problem and has no distinct cure. The present study was designed to investigate the antidiabetic, antioxidant and antilipidemic effects of Passiflora edulis flavicarpa extract (PefEt) against streptozotocin (STZ) induced diabetic rats. A total of forty wistar rats were randomly divided into four groups ( $\mathrm{n}=10 \mathrm{male}$ rats/group) as control; control+PefEt; diabetic and diabetic+PefEt. Streptozotocin was administered as a single dose $(50 \mathrm{mg} / \mathrm{kg}$ ) to induce diabetes. The effect of Passiflora edulis flawicarpa (PefEt-250 mg/kg bodyweight for four weeks) on diabetic rats was investigated by evaluating various biochemical parameters. The levels of blood glucose, C-peptide, insulin; enzymatic antioxidants, total antioxidant status, oxidative markers (Malondialdehyde and Urinary 8-hydroxydeoxyguanosine) and lipid profile were measured. Levels of glucose, MDA and urinary 8-OHdG were significantly decreased, while levels of antioxidants, C-peptide and insulin were significantly increased on administration of PefEt in the STZ-induced rats when compared to control groups. Therefore, it could be concluded that PefEt must be considered as an excellent herb for future studies on diabetes mellitus.
\end{abstract}

Keywords: antioxidant, blood glucose, lipid profile, Passiflora edulis, streptozotocin, urinary 8-OHdG

\section{Introduction}

Diabetes is a metabolic disorder due to absolute deficiency or diminished effectiveness of insulin. Due to lack of insulin, hyperglycemia and glycosuria almost invariably occur. The search for a curative agent against this disease resulted in the introduction of several hypoglycemic agents and some of which are used therapeutically. However, various harmful side effects and weak effectiveness of them made their use limited and the search to find more effective agents continues. Investigations in the plant kingdom culminated in the discovery of many herbal hypoglycemic agents. One of them is taken for investigation in this study.

Diabetes mellitus is a metabolic disorder characterized by chronic hyperglycemia and hyperlipidemia that predisposes affected individuals go long term micro- and macro vascular complications (Ahmed et al., 2007). Attention has been focused on the relationship between the productions of reactive oxygen species (ROS) in diabetes.

In Diabetes mellitus, hyperglycemia induces non-enzymatic glycation of protein through Maillard's reaction and the resulting products, such as Schiff base and Amadori products can lead to the production of ROS such as hydrogen peroxide and superoxide anion (Brownlee et al., 1984; Sakurai and Tsuchiya, 1988; Njoroge and Monnier, 1989). Experimental evidences suggest that the complication of diabetes is associated with oxidative stress that can induce lipid peroxidation can leads to the formation of free radicals. All these free radicals might play a role in DNA damage, protein modification reactions and lipid oxidative modification in diabetes (Sies, 1997).

Cells have enzymatic and non-enzymatic scavenger systems against theses free radicals. The imbalance between oxidant and antioxidant leads to oxidative damage in cells.

Expression of endogenous antioxidants sometimes not able to prevent oxidative damage, requiring the supply of exogenous antioxidants by consumption of dietary sources (Habib and Ibrahim, 2011). Despite of whole fruits and vegetables intake, certain non-edible parts could be a good alternative to add dietary bioactive compounds (Leite-Legatti et al., 2012).

Passiflora edulis is commonly known as yellow passion fruit. The leaves of $P$. edulis are deeply 3-lobed when matured. The interest in $P$. edulis has been increased because of its antioxidant compounds. Studies with leaves and stems have shown several phenolic compounds like orientin 2"-O-rhamnoside and luteolin 7-O-(2-rhamnosylglucoside) (Coleta et al., 2006), apigenin and luteolin derivatives (Ferreres et al., 2007). The polyphenols and flavonoids have antioxidant properties as they could neutralize reactive oxidants (Pietta, 2000) and hypoglycemic activity suggests that it will be of more helpful in controlling blood sugar level in diabetes (Devaki et al., 2011).

These findings demonstrated that the $P$. edulis leaf extract have potent in-vitro and ex-vivo antioxidant properties and might be considered as possible new sources of natural antioxidants (Rudnicki et al., 2007). Several studies have 
384

reported that the fruit of $P$. edulis has been used in the treatment of diabetes, mainly due to the presence of soluble fibers such as pectin (Krahn et al., 2008; Weickert and Pfeiffer, 2008; Salgado et al., 2010; Sandra et al., 2011; 2012; Correa et al., 2014; Sousa et al., 2015) but literature contains only few studies that used leaves and stem of the species $P$. edulis for their antioxidant effect (Rudnicki et al., 2007; da Silva et al., 2013) and hypoglycemic effect in diabetes rats (Devaki et al., 2011).

The literature survey has shown that many works has been carried out to verify the claims on the antioxidant (Farhana et al., 2009) and hypolipidemic (Maricelma et al., 2012) effect of $P$. edulis fruit extract in rats and rat models. The purpose of the study was to determine the effect of $P$. edulis leaf extract on oxidative stress, hyperglycemia and hyperlipidemia in STZ induced diabetic rats. So the present study clearly reveals that the leaves and stem extract of $P$. edulis have shown to reduce blood glucose after administration of STZ which confirms the hypoglycemic nature of the plant.

In the light of the above, the use of $P$. edulis leaf extract represents a therapeutic prospect for diabetes mellitus and also contributes to reduce free radicals and lipid peroxidation, which is also a highly positive factor for lowering the risk of cardio vascular diseases. In view of these facts, the present work aimed to evaluate the effect of $P$. edulis leave extract on biochemical profile of Wistar rats.

\section{Materials and Methods}

Animals

Male Wistar albino rats (5-8 weeks old), weighing 200-250 g were purchased from the Tamilnadu Veterinary Animal Science, Chennai, India were housed in polycarbonate cages in a room with a $12 \mathrm{~h}$ day-night cycle, temperature of $22 \pm 2^{\circ} \mathrm{C}$, fed with a standard pellet diet (VRK Nutritional Solution, Maharashtra, India) and water ad libitum.

The rats were handled according to the University and Institutional legislation, regulated by the ethical committee on animal care of Mahatma Gandhi Medical College and Research Institute, Puducherry (India). All the procedures performed on animals were approved and conducted in accordance with the National Institute of Health Guide (Reg. No. 686/02/2012/CPCSEA).

Source of chemicals

Streptozotocin was purchased from Sigma chemical company, St. Louis, Mo, USA. 8-OHdG ELISA kit was purchased from Cell Biolabs, Inc., San Diego, CA 92126, USA. All other chemicals used for the experiments were of analytical grade obtained from local firms.

\section{Plantmaterial}

P. edulis flavicarpa leaves and stems were collected from the Calicut, Kerala, India. The plant materials were authenticated by experts from the Botanical Department, Annamalainagar, Chidambaram where a voucher specimen has been deposited. (PefEt)

Preparation of ethanolic extract of Passiflora edulis flavicarpa

The fresh leaves and stems were collected and sun dried for seven days. The $50 \mathrm{~g}$ of this powder was mixed with $300 \mathrm{ml}$ ethanol for 24 hours. The extract was filtered using a muslin cloth and concentrated under the room temperature. The solution was evaporated giving a fine residue. The yield of the extract was $20 \%$ and the preliminary phytochemical screening was done by using standard procedure and the extract was tested for alkaloids, phenols, glycosyl flavonoids and cyanogenic compounds. The residual extract was dissolved in sterile water and used in the investigation. The previous study by Ana Beatriz et al. (2007) confirmed that a dose of $250 \mathrm{mg} / \mathrm{kg}$ PefEt was found to be effective. Hence, a dose $250 \mathrm{mg} / \mathrm{kg}$ PefEt was orally administered daily for 4 weeks.

\section{Induction of diabetes}

Wistar rats were made diabetic by oral injection of STZ ( 50 $\mathrm{mg} / \mathrm{Kg}$ bodyweight) dissolved in $0.05 \mathrm{M}$ citrate buffer, $\mathrm{pH} 4.5$ according to Ketan et al. (2006). Three days after the injection, blood glucose level was estimated. The rats were considered diabetics when fasting blood glucose level was more than 140 $\mathrm{mg} \%$.

\section{Blood collection}

One $\mathrm{ml}$ of blood drawn from lateral tail vein was collected in a herparinized tube and then centrifuged at $3000 \mathrm{rpm}$ for $10 \mathrm{~min}$ to obtain plasma for the estimation of TAS, TBARS, lipid profile and FBS. Enzymatic antioxidants were estimated with hemolysate.

\section{Urine collection}

One hundred and fifty $\mu \mathrm{L}$ of urine was collected in a sterile container for the analysis of urinary 8-hydroxydeoxyguanosine (8-OHdG). The rats were housed individually in metabolic cages for 24 hours to collect urine then centrifuged at $2000 \mathrm{rpm}$ for 10 min and supernatants were collected and stored at $-20{ }^{\circ} \mathrm{C}$ until assayed for the urinary 8-OHdG (Perline, 1971).

\section{Experimental desion} each:

Animals were randomly divided into four groups of ten rats

Group I: Control rats were orally injected with the same volume of citrate buffer ( $\mathrm{pH}$ 4.5). Group II: Control rats treated with PefEt alcoholic extract $(250 \mathrm{mg} / \mathrm{kg} /$ bodyweight $)$ daily by oral administration for 4 weeks.

Group III: Rats were made diabetic by oral injection of streptozotocin $(50 \mathrm{mg} / \mathrm{kg}$ bodyweight) dissolved in 0.05 citrate buffer ( $\mathrm{pH} 4.5)$.

Group IV: Diabetic rats treated with PefEt alcoholic extract (250 mg/kg/bodyweight) daily by oral administration for 4 weeks.

\section{Biochemical assay}

Blood glucose was estimated by portable glucometer (One Touch Ultra, Jhonson and Johnson). C-Peptide as well as insulin was estimated in sera by ELISA kit by the method of Kao et al. (1994); Ashby and Frier (1981) respectively.

\section{Measurement of oxidative markers}

Lipid peroxidation product, thiobarbituric acid reactive species (TBARS) was determined by Ohkawa et al.(1979).

Urinary 8-OHdG: Urine specimens were used for the measurement of the 8-OHdG levels using a competitive in-vitro enzyme-linked immunosorbent assay (ELISA) kit (Cell Biolabs, 
Inc., San Diego, CA 92126, USA). The detection range of the ELISA assay was 0 to $20 \mathrm{ng} / \mathrm{mL}$. The urinary $8-\mathrm{OHdG}$ was expressed as total amounts excreted in $24 \mathrm{~h}$.

\section{Measurement of antioxidant status}

Antioxidants such as Superoxide dismutase (SOD), catalase (CAT) and glutathione peroxidase (GPx) were assayed by the method of Kakkar et al. (1984), Sinha (1972) and Rotruck et al. (1973) respectively. Total antioxidant status of serum was determined by ferric reducing antioxidant power assay (Benzie and Strain, 1996; Cevahir, 2002), whereby at low $\mathrm{pH}$, reduction of a ferric tripyridyl triazine ( $\mathrm{Fe}^{3+}$-TPTZ) complex (Sigma Aldrich, St. Louis, MO, USA) to a ferrous form, which has an intense blue color, that can be monitored by measuring the absorbance at $593 \mathrm{~nm}$ using spectrophotometer. It is directly related to the combined or total reducing power of the electron donating antioxidants present in the reaction mixture. The results were expressed as micro mole per liter.

\section{Measurement of lipid profile}

Plasma triglycerides, total cholesterol, LDL and HDL and fasting glucose concentration were measured with an auto analyzer (Randox Daytona, clinical biochemistry analyzer) by using IFCC approved commercial kits. VLDL was calculated by Friedwald equation.

\section{Statistical analysis}

All data measurements were expressed as mean \pm SD for control and experimental animals. Statistical comparisons were performed using one way analysis of variance (ANOVA) test which was applied for multigroup comparison. Comparison of different variables in various groups was carried out using Post Hoc LSD multiple comparisons. Pearson's correlation test was used for correlating oxidant and TAS variables. For all tests a probability $(\mathrm{p}<0.05)$ was considered significant. The data analysis was carried out by using statistical package of social science (SPSS) version 12 for windows.

\section{Results}

The present study revealed that the induction of diabetes using streptozotocin (STZ) caused a significant increase in blood glucose levels and inversely significant decrease in serum insulin and C-peptide as compared to the control group. Oral administration of PefEt significantly reduced blood glucose level reaching about $50 \%$.

The changes in the lipid profile of normal and STZ-induced rats are illustrated in Table 1 . Untreated diabetic rats were characterized by a significant elevation in the levels of total cholesterol, triacylglycerols, LDL cholesterol and VLDL cholesterol compared with the control rats. Diabetic rats treated with PefEt showed near normal levels of lipid profile. Significantly $(p<0.05)$ decreased levels of serum HDL cholesterol were observed in diabetic rats when compared with the non-diabetic rats. Administration of PefEt to diabetic rats significantly increased serum HDL cholesterol, when compared with STZ-induced rats.

The status of enzymatic antioxidants (SOD, GPX, CAT, ) and total antioxidant status were measured in erythrocyte lysate and plasma respectively in all experiment groups are depicted in Table 2. Activities of enzymatic antioxidants were markedly reduced in diabetic rats compared with control and control treated groups. The induction of diabetes using streptozotocin developed a state of oxidative stress as denoted by a significant increase in TBARS and DNA damage represented by $8-\mathrm{OHdG}$. The treatment of diabetic rats with PefEt led to a significant decrease in serum levels of lipid hydroperoxide. However, the antioxidant enzyme activity and TAS was significantly higher in the PefEt treated diabetic group when compared to the untreated diabetic rats. PefEt administration to normal rats did not alter the activity of enzymatic antioxidants (SOD, CAT, GPX).

The correlation analysis between total antioxidant status and urinary 8-OHdG was depicted in the Fig. 1 which revealed a significant negative correlation in all the four groups (control: $r=-$ 0.9346; PefEt: $r=-0.9491$; diabetic: $r=-0.8311$; DM+PefEt: $r=-$ 0.9057). The treatment of diabetic rats with PefEt led to a significant decrease in urinary $8-\mathrm{OHdG}$ levels with significant increase in total antioxidant levels compared to untreated diabetic rats.

\section{Discussion}

Diabetes is characterized by hyperglycemia with diminished secretion of insulin and its function. Over a long period, diabetes generates a larger number of reactive oxygen species (ROS) which induces oxidative stress. There were many reasons for increased oxidative damage. In case of diabetes mellitus, hyperglycemia itself contributes to increased generation of ROS by producing reactive ketoimine and ketoamine adducts during oxidative glycosylation and glycoxidation, which further produce ROS (Park et al., 2001). Enhanced oxidative stress may be closely related to pathogenesis of diabetic macro and micro angiopathy by exerting direct oxidative stress (Nishikawa et al., 2000).

In the diabetic state, increased ROS production and decreased antioxidant capacity has been observed in many studies

Table 1. Fasting blood sugar, insulin, C-peptide and lipid profile in the different studied groups

\begin{tabular}{|c|c|c|c|c|}
\hline Groups & Control & PefEt & Diabetic & Diabetic \pm PefEt \\
\hline Glucose $(\mathrm{mg} / \mathrm{dL})$ & $94.1 \pm 10.8$ & $86.1 \pm 9.8$ & $271.9 \pm 49.4^{\mathrm{a}}$ & $122.9 \pm 32.4^{\mathrm{b}}$ \\
\hline C-Peptide (ng/mL) & $0.051 \pm 0.012$ & $0.077 \pm 0.028$ & $0.025 \pm 0.009^{a}$ & $0.038 \pm 0.006^{b}$ \\
\hline Insulin $(\mu \mathrm{IU} / \mathrm{mL})$ & $1.86 \pm 0.22$ & $2.81 \pm 0.42$ & $0.93 \pm 0.21^{\mathrm{a}}$ & $1.42 \pm 0.25^{b}$ \\
\hline \multicolumn{5}{|l|}{ Lipid Profile } \\
\hline Total Cholesterol (mg/dL) & $68.04 \pm 0.11$ & $60.12 \pm 10.8$ & $87.30 \pm 0.26^{\mathrm{a}}$ & $70.1 \pm 0.31^{b}$ \\
\hline $\mathrm{TAG}(\mathrm{mg} / \mathrm{dL})$ & $83.96 \pm 0.27$ & $70.24 \pm 0.41$ & $175.61 \pm 1.72^{\mathrm{a}}$ & $85.88 \pm 0.29^{b}$ \\
\hline LDL Cholesterol (mg/dL) & $21.45 \pm 0.21$ & $16.01 \pm 0.08$ & $31.21 \pm 0.13^{\mathrm{a}}$ & $23.01 \pm 0.16^{\mathrm{b}}$ \\
\hline VLDL Cholesterol (mg/dL) & $16.79 \pm 0.05$ & $14.04 \pm 0.08$ & $35.12 \pm 0.34^{\mathrm{a}}$ & $17.17 \pm 0.05^{b}$ \\
\hline HDL Cholesterol (mg/dL) & $28.79 \pm 0.18$ & $34.48 \pm 0.19$ & $17.58 \pm 0.11^{\mathrm{a}}$ & $29.78 \pm 0.12^{\mathrm{b}}$ \\
\hline
\end{tabular}

Values are given as mean $\pm \mathrm{SD}$ in each group.

$a=$ Statistical significant difference between diabetic and control rats at $(\mathrm{p}<0.05)$.

$\mathrm{b}=$ Statistical significant difference between diabetic rats treated with PefEt and the diabetic at $(\mathrm{p}<0.05)$. 
Table 2. Antioxidants, MDA and urinary 8-OHdG in the different studied groups

\begin{tabular}{|c|c|c|c|c|}
\hline Groups & Control & PefEt & Diabetic & Diabetic + PefEt \\
\hline $\mathrm{SOD}\left(\mathrm{U}^{\mathrm{A}} / \mathrm{mg} \mathrm{Hb}\right)$ & $8.10 \pm 0.48$ & $8.16 \pm 9.2$ & $4.13 \pm 0.31^{\mathrm{a}}$ & $8.15 \pm 0.48^{\mathrm{b}}$ \\
\hline $\operatorname{CAT}\left(\mathrm{U}^{\mathrm{B}} / \mathrm{mg} \mathrm{Hb}\right)$ & $142.01 \pm 11.15$ & $140.41 \pm 11.18$ & $71.23 \pm 10.11^{\mathrm{a}}$ & $93.82 \pm 12.98^{b}$ \\
\hline $\mathrm{GPX}\left(\mathrm{U}^{\mathrm{C}} / \mathrm{mg} \mathrm{Hb}\right)$ & $26.31 \pm 1.26$ & $24.01 \pm 1.22$ & $9.39 \pm 1.71^{\mathrm{a}}$ & $21.42 \pm 2.15^{b}$ \\
\hline TAS $(\mu \mathrm{M} / \mathrm{L})$ & $1129 \pm 148.8$ & $1131 \pm 174.9$ & $779 \pm 127.4^{\mathrm{a}}$ & $1090 \pm 128.4^{b}$ \\
\hline TBARS $(\mathrm{nM} / \mathrm{mL})$ & $1.31 \pm 0.24$ & $1.30 \pm 0.19$ & $2.64 \pm 0.22^{\mathrm{a}}$ & $1.38 \pm 0.41^{\mathrm{b}}$ \\
\hline Urinary 8-OHdG (ng/day) & $5.41 \pm 0.91$ & $4.98 \pm 0.89$ & $27.29 \pm 5.60^{\mathrm{a}}$ & $11.25 \pm 3.35^{b}$ \\
\hline
\end{tabular}

Values are given as mean \pm SD in each group.

$a=$ Statistical significant difference between diabetic and control rats at $(\mathrm{p}<0.01)$.

$\mathrm{b}=$ Statistical significant difference between diabetic rats treated with PefEt and the diabetic at $(\mathrm{p}<0.01)$.

$\mathrm{U}^{\mathrm{A}}=$ enzyme concentration required to inhibit to $50 \%$ in one minute

$\mathrm{U}^{\mathrm{B}}=\mu \mathrm{M}$ of $\mathrm{H} 2 \mathrm{O} 2$ consumed $/$ minute

$\mathrm{U}^{\mathrm{C}}=\mu \mathrm{g}$ of GSH utilized $/$ minute

TAS-Total Antioxidant Status:

TBARS-Thiobarbituric acid reactive substances

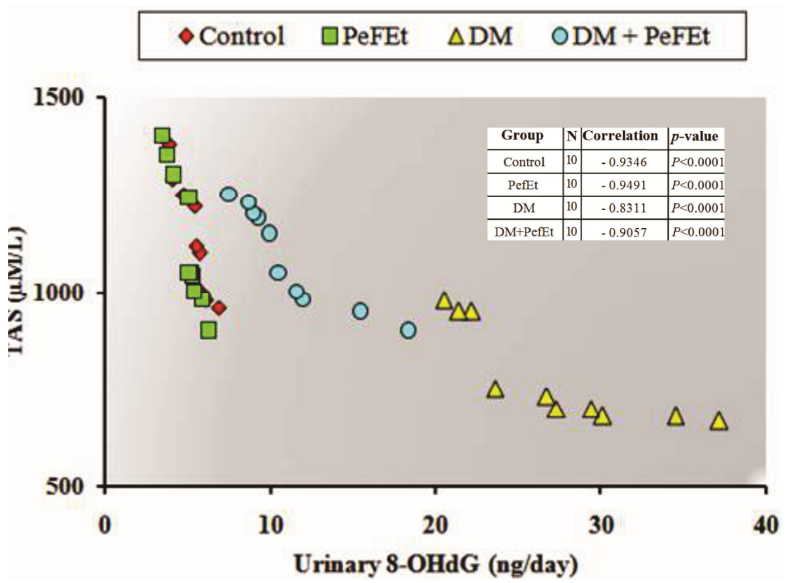

Fig. 1. The correlation of urinary $8-\mathrm{OHdG}$ with TAS

The urinary $8-\mathrm{OHdG}$ was independently correlated with TAS in all the groups. The negative correlation was highly significant $(\mathrm{p}<0.0001)$ in all the four groups.

(Oberley, 1988; Baynes, 1991; Giugliano et al., 1996; Durdi and Timur, 2007). ROS generated during metabolism can enter into reactions that when uncontrolled, can affect certain processes leading to clinical manifestations (Winkler and Moser, 1992; Halliwell, 1993; Kesavulu et al., 2000).

In common, oxidative stress can affect various bio-molecules, mainly nucleic acid results in the generation of modified bases in DNA. 8-OHdG often plays a crucial role in mutagenesis (Kuchino et al., 1987). Elevated levels of 8-OHdG have been reported in urine (Leinonen et al., 1997; Hinokio et al., 1999), mononuclear cells (Dandona et al., 1996), and skeletal muscles (Suzuki et al., 1999) of diabetic patients. In previous studies, the levels of 8-OHdG increased in kidney tissues of STZ-induced diabetic rats (Fraga et al., 1990; Ha et al., 1994).

Several studies demonstrated that a plasma 8-OHdG level was increased in diabetic patients (Kasai $e t$ al., 1986; Richter et al., 1988; Shigenaga et al., 1989; Shin et al., 2001). In agreement with previous studies, STZ induced rats had significantly higher levels of 8-OHdG compared with control rats in the present study. This finding suggests that urinary 8OHdG is a more sensitive marker for oxidative DNA damage. The lipid peroxidation in cells is controlled by various cellular defense mechanisms consisting of enzymatic scavenger system (Halliwell and Gutterridge, 1994).

Lipid peroxidation leads to oxidation of polyunsaturated fatty acids and forms root cause for variety of diseases including cancer, diabetes and cardiovascular disorders (Amina and Hamza, 2006). The present results showed a significant increase in lipid peroxidation in plasma and RBC of rats treated with STZ. This confirms the previous report on the ability of this diabetogenic compound to induce oxidative damage through generation of free radicals (Sakudelski, 2001).

Enzymatic antioxidants such as SOD, CAT and GPx and TAS provide protection against ROS. Decrease in the antioxidant activity results in the accumulation of lipid peroxides and increase oxidative stress in diabetic rats (Hicks et al., 1988; Johansen et al., 2005). The enzymatic antioxidants were significantly reinstated to near normal in PefEt treated rats. This signifies the antioxidant effect of PefEt in scavenging the free radicals.

A large no of plant derived products as a cure for hyperglycemia in ever growing. The present study confirms the antihyperglycemic, antihyperlipidemia and antioxidant effect of Passiflora edulis flavicarpa extract in STZ induced rats. Administration of PefEt to diabetic rats significantly reduced the blood glucose levels to near normal.

The administration of PefEt to diabetic rats significantly reduced MDA, a marker of lipid peroxidation suggesting the antioxidant property of the extract. Previous studies have shown that various plant extract can also stimulate the synthesis of cellular antioxidants (Ahmed and Sharma, 1997; Essa and Subramanian, 2006). The phytochemical screening of PefEt revealed the presence of flavonoids and polyphenols, which plays an important role as natural antioxidants for the prevention of oxidative damage. It is believed that phenolic antioxidants can scavenge deleterious free radicals and prevent their oxidative reactions with vital biological molecules (Rice-Evens et al., 1996).

The administration of Passiffor edulis flavicarpa extract (PefEt) reduced MDA, a marker of lipid peroxidation in the diabetic rats suggesting that the extract possesses potent antioxidative properties. The levels of lipid peroxidation in cells are controlled by free radical scavenging system (Gutteridge, 1995; Tho, 1988). SOD, CAT, GPx and TAS constitute a mutually supportive of defense against ROS. Decreased activity of these antioxidant enzymes results in the accumulation of lipid peroxides and increase oxidative stress in diabetic rats. The level of these antioxidants was significantly restored to near normal after treatment of PefEt.

In the present study PefEt is a source of many potentially active antioxidants and active constituents, such as flavonoid, glycosides, hibiscetin cyandine, cyanine glycoside. This would be the reason for the enhanced activities of antioxidant levels in extract treat groups. 
During diabetic conditions lipogenesis is decreased while lipolysis is increased in the hepatic tissue. The increased level of cholesterol is due to the decreased level of high density lipoprotein (HDL) cholesterol. The antihyperlipidemic effect shown by the PefEt extract was also in accordance with earlier findings. Significantly lowering of total cholesterol and rise in HDL cholesterol in biochemical state for prevention of atherosclerosis (Schwab, 2000).

Several research work suggest that Passiflora edulis species is well known to possess anxiolytic (Deng et al., 2010), cytotoxic, antioxidant and anti-inflammatory effect (Ana Beatriz et al., 2007), but very few work done in diabetes mellitus and lipid profile and no work was done in Passiflora edulis as a preventing tool for DNA damage. In the present study, we have shown a correlation between urinary 8-OHdG and TAS. This suggests that urinary $8-\mathrm{OHdG}$ may be a useful biomarker for the assessment of oxidative DNA damage in diabetic patients. Our data suggests that PefEt would be helpful for the reduction of blood glucose and oxidative DNA damage in diabetes.

\section{Conclusions}

The present study reinforces that, Passiflora edulis flavicarpa extract revealed antioxidant, antihyperglycemic and antihyperlipidemic activities without showing any toxic effects and serves as natural remedy against hyperglycemia that can be used for prevention of diabetic vascular complications. Further studies on the characterization and the active principles responsible for antidiabetic activity of Passiflora edulis flavicarpa are highly warranted.

\section{References}

Ahmed KA, Muniandy S, Ismail IS (2007). Role of N-(carboxymethyl) lysine in the development of ischemic heart disease in type 2 diabetes mellitus. Journal of Clinical Biochemistry and Nutrition 41(2):97105.

Ahmed RS, Sharma SB (1997). Biochemical studies on combined effects of garlic (Allium sativum) and ginger (Zingiber officinales rose) in albino rats. Indian Journal of Experimental Biology 35:841843.

Amina A, Hamza AA (2006). Hepatoprotective effects of Hibiscus, Rosmarinus and Salvia on azathioprine-induced toxicity in rats. Life Sciences 77(3):266-278.

Ana Beatriz M, Silvana MZ, Eloir PS, Tania SF (2007). Evidence of anti-inflammatory effects of Passiflora edulis in an inflammation model. Journal of Ethnopharmacology 109(2):281-288.

Ashby J, Frier B (1981). Circulating c-peptide: measurement and clinical applications. Annals of Clinical Biochemistry 18:125.

Baynes JW (1991). Role of oxidative stress in development of complications in diabetes. Diabetes 40:405-412.

Benzie IF, Strain JJ (1996). The ferric reducing ability of plasma (FRAP) as a measure of antioxidant power: the FRAP assay. Analytical Biochemistry 239:70-76.

Brownlee M, Vlassara H, Cerami A (1984). Nonenzymatic gycosylation and the pathogenesis of diabetic complications. Annals of Internal Medicine 101:527-537.
Cevahir E (2002). The evaluation of oxidative stress in patients with CRF. Clinica Chimica Acta 322:157-167.

Coleta M, Batista MT, Campos MG, Carvalho R, Cotrim MD, de Lima TCM, da Cunha AP (2006). Neuropharmacological evaluation of the putative anxiolytic effects of Passiflora edulis sims, its sub-fractions and flavonoid constituents. Phytotherapy Research 20(12):1067-1073.

Correea EM, Medina L, Monteiro BJ, Valle NO, Sales R, Magalaes A, Carvalho RP (2014). The intake of fiber mesocarp passionfruit (Passiflora edulis) lowers levels of triglyceride and cholesterol decreasing principally insulin and leptin. The Journal of Aging Research and Clinical Practice 3(1):31-35.

da Silva JK, Cazarin CBB, Colomeu TC, Batista AG, Meletti LMM, Paschoal JAR, Zollner RL (2013). Antioxidant activity of aqueous extract of passion fruit (Passiflora edulis) leaves: in vitro and in vivo study. Food Research International 53:882-890.

Dandona P, Thusu K, Cook S, Snyder B, Makowski J, Armstrong D, Nicotera T (1996). Oxidative damage to DNA in diabetes mellitus. Lancet 347:444-445.

Deng J, Yujuan Z, Mengmeng B, Hongwei L, Li L (2010). Anxiolytic and sedative activities of Passiflora edulis f. flavicarpa. Journal of Ethnopharmacology 128(1):148-153.

Devaki K, Beulah U, Akila G, Sunitha M, Gopalakrishnan VK (2011). Hypoglycemic activity of Passiflora edulis sims leaf extract in wistar albino rats. International Research Journal of Pharmacy 2(9):170172.

Durdi Q, Timur R (2007). Catalase (antioxidant enzyme) activity in streptozotocin-induced diabetic rats. International Journal of Diabetes and Metabolism 15:22-24.

Essa MM, Subramanian P (2006), Effect of Hibiscus sabdariffa on lipid peroxidation in hyperammonmic rats. Journal of Cell and Tissue Research 6(2):819-823.

Farhana AR. Mahmuda H, Laizuman N, Monirul Isalm Md (2009). Antibacterial, cytotoxic and antioxidant activity of Passiflora edulis sims. European Journal of Scientific Research 31:592-598.

Ferreres F, Sousa C, Valentao P, Andrade PB, Seabra RM, Gil-Izquierdo A (2007). New C-deoxyhexosyl flavones and antioxidant properties of Passiflora edulis leaf extract. Journal of Agricultural and Food Chemistry 55:10187-10193.

Fraga CG, Shigenaga MK, Par JW, Degan P, Ames BN (1990). Oxidative damage to DNA during aging: 8-hydroxy-2'deoxy guanosine in rats organ DNA and urine. Proceedings of the National Academy of Sciences USA 87:4533-4537.

Giugliano D, Ceriello A, Paolisso G (1996). Oxidative stress and diabetic complications. Diabetic Care 19:257-267.

Gutteridge JMC (1995). Lipid peroxidation and antioxidants as biomarkers of tissue damage. Clinical Chemistry 41:1819-1828.

$\mathrm{Ha}$ H, KimC, Son Y, Chung MH, Kim KH (1994). DNA damage in the kidneys of diabetic rats exhibiting microalbuminuria. Free Radical Biology and Medicine 16:271-274.

Habib HM, Ibrahim WH (2011). Effect of date seeds on oxidative damage and antioxidant status in vivo. Journal of the Science of Food and Agriculture 91(9):1674-1679. 
388

Halliwell B (1993). The role of oxygen radicals in human disease with particular reference to the vascular system. Haemostasis 23:118-126.

Halliwell B, Gutteridge JMC (1994). Free radicals in biology and Medicine. $3^{\text {rd }}$ Ed, Oxford Science Publication.

Hicks M, Delbridge L, Yue DK, Reeve TS (1988). Catalysis of lipid peroxidation by glucose and glycosylated protein. Biochemical and Biophysical Research Communications 151:649-655.

Hinokio Y, Suzuki S, Hirai M, Chiba M, Hirai A, Toyota T (1999). Oxidative DNA damage in diabetes mellitus: its association with diabetic complications. Diabetologia 42:995-998.

Johansen JS, Harris AK, Rychly DJ, Ergul A (2005). Oxidative stress and the use of antioxidant in diabetes: linking basic science to clinical practice. Cardiovascular Diabetology 29:45.

Kakkar P, Das B, Viswanathan PN (1984). A modified spectrophotometric assay of superoxide dismutase. Indian Journal of Biochemistry and Biophysics 21:130-132.

Kao PC, Taylor RL, Service FJ (1994). Proinsulin by immunochemiluminometric assay for the diagnosis of insulinoma. Journal of Clinical Endocrinology and Metabolism 78(5):10481051.

Kasai H, Crain PF, Kuchino Y, Nishimura S, Otsuyama A, Tanooka $\mathrm{H}$ (1986). Formation of 8-hydroxyguanosine moiety in cellular DNA by agents producing oxygen radicals and evidence for its repair. Carcinogenesis 7:1849-1851.

Kesavulu MM, Giri R, Kameswara Rao B, Apparao C (2000). Lipid perxoiddation and antioxidant enzyme levels in type 2 diabetics with microvascular complications. Diabetes and Metabolism 26(5):387-392.

Ketan PM, Santosh LV, Ramesh KG, Parloop AB (2006). Beneficial effect of co-enzyme Q10 in streptozotocin-induced type-1 diabetic rats. Iranian Journal of Pharmacology and Therapeutics 5(1):61-65.

Krahn C, Braga A, Zimmer A, Verlindo AB (2008). Passion fruit (Passiflora edulis) dehydrated bark and its aqueous extract evaluation on glucose blood levels decrease induced in alloxan-diabetic rats. Brazilian Journal of Pharmacology 89:32-34.

Kuchino Y, Mori F, Kasai H, Inoue H, Iwai S, Miura K, Mishimura S (1987). Misreading of DNA templates containing 8hydroxydeoxyguanosine at the modified base and at adjacent residues. Nature 327:77-79.

Leinonen J, Lehtimaki T, Toyokuni S, Okada K, Tanaka T, Hiai H, Alho H (1997). New biomarker evidence of oxidative DNA damage in patients with non-insulin-dependent diabetes mellitus. FEBS Lett 417:150-152.

Leite-Legatti AV, Batista AG, Dragano NRV, Marques AC, Malta LG, Riccio M, Junior MRM (2012). Jaboticaba peel: antioxidant compounds, antiproliferative and antimutagenic activities. Food Research International 49(1):596-603.

Maricelma SSS, Sandra MB, Debora CD, Marilza VCR, Kleber EC, Ana Carolina GM, Vinicius CD (2012). Effects of Passiflora edulis (yellow passion) on serum lipids and oxidative stress status of wistar rats. Journal of Medicinal Food 15(1):78-82.

Nishikawa T, Edelstein D, Du XL, Yamagishi S, Matsumura T, Kaneda Y, Brownlee M (2000). Normalizing mitochondrial superoxide production blocks three pathways of hyperglycaemic damage. Nature 404:787-790.
Njoroge FG, Monnier VM (1989). The chemistry of the maillard reaction under physiological conditions: a review. Progress in Clinical Biological Research 304:85-107.

Oberley Lw (1988). Free radicals and diabetes. Free Radical Biology and Medicine 5:113-124.

Ohkawa H, Ohishi N, Yagi K (1979). Assay for lipid peroxides in animal tissues by thiobarbituric acid reaction. Analytical Biochemistry 95(2):351-358.

Park KS, Kim JH, Kim MS, Kim SK, Choi JY, Chung MH, Lee HK (2001). Effect of insulin and antioxidant on plasma 8hydroxyguanine and tissue 8-hydroxydeoxyguanosine in streptozotocin-induced diabetic rats. Diabetes 50(12):2837-2841.

Perline IH (1971). An inexpensive mouse urine collection system. Physiology and Behaviour 6(5):597.

Pietta PG (2000). Flavonoids as antioxidants. Journal of Natural Products 63(7):1035-1042.

Rice-Evens CA, Miller WJ, Paganga G (1996). Structure antioxidant activity relationship of flavonoids and phenolic acids. Free Radical Biology and Medicine 20:933-956.

Richter C, Park JW, Ames BN (1988). Normal oxidative damage to mitochondrial and nuclear DNA is extensive. Proceedings of the National Academy of Sciences USA 85:6465-6467.

Rotruck JJ, Pope AL, Ganther HE, Swanson AB (1973). Selenium: biochemical rates as a component of glutathione peroxidase. Science 179:588-590.

Rudnicki M, de Oliveira MR, Pereira TD, Reginatto FH Dal-Pizzol F, Moreira J (2007). Antioxidant and antiglycation properties of Passiflora alata and Passiflora edulis extracts. Food Chemistry 100(2):719-724.

Sakudelski T (2001). The mechanism of alloxan and streptozotocin action in B cells of the rat pancreas. Physiological Research 50:537546.

Sakurai T, Tsuchiya S (1988). Superoxide production from nonenzymatically glycated protein. FEBS Lett 236:406-410.

Salgado JM, Bombarde TAD, Mansi DN, Piedade MS, Meletti LMM (2010). Effect of different concentration of passion fruit peel (Passiflora edulis) on the glicemic control in diabetic rat. Cienciae Tecnologia de Alimentos 30(3):784789.

Sandra MB, Debora CD, Ana PMS, Ira Eliane RNL, Adriano CA, Elen LG, Claudemir GM (2011). Effects of Passiflora edulis on the metabolic profile of diabetic wistar rat offspring. Journal of Medicinal Food 14(12):1490-1495.

Sandra MB, Maricelma SSS, Julio CPS, Claudmir GM, Gabriela AO, Tainara C, Flavia MVFM (2012). Yellow passion fruit rind (Passiflora edulis): an industrial waste or an adjuvant in the maintenance of glycemia and prevention of dyslipidemia? Journal of Diabetic Research and Clinical Metabolism (1):1-4.

Schwab US (2000). Dietary cholesterol increases the susceptibility of low density lipoprotein to oxidative modification. Atherosclerosis 149:83-90.

Shigenaga MK, Gimeno CJ, Ames BN (1989). Urinary 8-hydroxy2 'deoxy guanosine as a biologic marker of in vivo oxidative DNA damage. Proceedings of the National Academy of Sciences USA 86:9697-9701. 
Shin CS, Moon BS, Park KS, Kim SY, Park SJ, Chung MH, Lee HK (2001). Serum 8-hydroxyguanosine levels are increased in diabetic patients. Diabetes Care 24:733-737.

Sies H (1997). Oxidative stress: Oxidants and antioxidant. Experimental Physiology 82:291-295.

Sinha KA (1972). Colorimetric assay of catalase. Analytical Biochemistry 47:389-394.

Sousa RVRB, Guedes MIF, Marques MMM, Viana DA, Silav ING, Rodrigues PAS, Vieira IGP (2015). Hypoglycemic effect of new pectin isolated from Passiflora glandulosa cav in alloxan induced diabetic mice. World Journal of Pharmacy and Pharmaceutical Sciences 4(1):1571-1586.

Suzuki S, Hinokio Y, Komatu K, Ohtomo M, Onoda M, Hirai S, Toyota T (1999). Oxidative damage to mitochondrial DNA and its relationship to diabetic complications. Diabetes Research and Clinical Practice 45:161-168.
Tho LL, Candlish JK, Thai AC (1988). Correlates of diabetes markers with erythrocytic enzymes decomposing reactive oxygen species. Annals of Clinical Biochemistry 25:426-431.

Weickert MO, Pfeiffer AF (2008). Metabolic effects of dietary fiber consumption and prevention of diabetes. The Journal of Nutrition 138(3):439-442.

Winkler R, Moser M (1992). Alterations of antioxidant tissue defense enzymes and related metabolic parameters in streptozotocindiabetic rats--effects of iodine treatment. Wiener Klinische Wochenschrift 104(14):409-413. 